\title{
Fatigue life and crack growth behavior of post welded Aluminum 5183 alloy
}

\author{
Vidit Gaur ${ }^{1, *}$, Manabu Enoki ${ }^{1}$, Toshiya Okada $^{2}$ and Syohei Yomogida ${ }^{2}$ \\ ${ }^{1}$ Department of Materials Engineering, The University of Tokyo, 7-3-1 Hongo, Bunkyo-ku, Tokyo, 113-8656, Japan \\ ${ }^{2}$ Research \& Development Division, UACJ Corporation, 3-1-12 Chitose, Minato-ku, Nagoya-city, Aichi Pref. 455-8670, Japan
}

\begin{abstract}
In this study we investigated the fatigue life and crack growth behavior of $\mathrm{Al}$ 5183 alloy. Microscopic analysis revealed nearly equi-axed grains and no texture in longitudinal or cross-sectional plane of the welded plates. Gas porosities with an average size of $45 \mu \mathrm{m}$, comparable to grain size $(55 \mu \mathrm{m})$, were present and often initiate fatigue failures. Load-controlled cyclic tests at different stress-ratios $(R=-1,-0.5,0.1,0.5 .0 .7$ and 0.8 ) revealed decrease in fatigue lives with increase in $R$-ratio. At $R>0.7$, no fatigue failure could be observed, suggesting a probable mean-stress saturation effect on fatigue. Mean stress also tends to control the crack initiation sites: surface initiated failures at low mean stresses while sub-surface pores induced failures at higher mean stresses. Fatigue-crack growth tests on CT specimens at different R-ratios $(0.1,0.5$ and 0.8$)$ revealed reduction in crack growth rates (and in threshold values) with increasing $\mathrm{R}$-ratio. The $\Delta \mathrm{K}$ applied for pores responsible for fatigue failures were often lower than or near to the threshold values and also, the size of such pores was of order of magnitude of grain size, thus crack initiated from pores are short cracks and further tests are progress.
\end{abstract}

\section{Introduction}

Welded structures are generally weaker under fatigue than the base material because of the stressconcentration factor arising from weld shape or nonwelded root gaps, weld defects and change in properties of weld area. Many welding techniques exist such as Friction stir welding (FSW) [1], fiber laser-Metal Inert Gas (MIG) hybrid welding [2], MIG welding, Tungsten inert gas (TIG) welding. Among them, FSW (a solidstate welding technique), is the most effective one. TIG and MIG welding often results in reduction of fatigue strength [3-4] due to welding defects such as porosity, hot cracking, tensile residual stresses, distortion, etc. Porosities are most commonly encountered defects and act as stress raisers thus lowering down the crack nucleation period significantly depending upon their size, shape, position and reduce the fatigue lives [5]. Most of the experimental studies on fatigue behavior of metal alloys containing defects revealed the crack initiation from pores, specifically located at or near to the surface [6-7]. Nearly all of these studies were done at constant R-ratio and less data is available on influence of mean stress on fatigue behavior and damage mechanisms for fatigue cracks initiating from natural defects [8-9].
In this study we investigated the fatigue life and crack growth behavior of Al-5183 alloy, post welding of Al-5083 (base metal). Al-5xxx alloys are commonly used, high-strength and non-heat treatable aluminummagnesium alloys. MIG welding is still preferable choice for such type of alloys [10]. $50 \mathrm{~mm}$ thick Al-Mg alloy (Al-5083) plates with $90^{\circ}$ weld groove angle of double-V type butt joint were welded using single pass MIG welding and using Al-5183 as filler-wire material.

Load-controlled fatigue tests were conducted on the cylindrical specimens taken out from the weld bead (fusion part), at different stress ratios (R-ratios = $\left.\sigma_{\min } / \sigma_{\max }\right)$, followed by fracture surface examination. A modified Walker's model [11] provided the best prediction of fatigue lives and endurance limit than any of the existing models. For crack growth tests, standard CT specimens were extracted from the welded part such that the notch of the CT specimen lies along the weld bead and the crack propagation plane is same as in cylindrical specimens. Both $\Delta \mathrm{K}$-decreasing and $\Delta \mathrm{K}$ increasing tests were done in the range of $10^{-10} \mathrm{~m} /$ cycle to $10^{-6} \mathrm{~m} /$ cycle.

The overall aim of this study is to investigate the composition of crack initiation and crack growth in total fatigue life of the material containing pores (or defects) and finally be able to predict the total fatigue life

Corresponding author: gaur@rme.mm.t.u-tokyo.ac.jp 
including the mean stress correction and to develop an extensible computational framework by integrating the advanced computational techniques such as crystal plasticity modelling for crack initiation prediction, extended finite element method for crack growth etc.

\section{Material}

The material investigated in this study is Al-5183 alloy (filler metal) post-welding of Al-5083 (base metal). The chemical composition of base metal (Al-5083) and filler material (Al-5183) is shown in Table 1 and the respective tensile properties are reported in Table 2 . The micro-structure was analyzed along the weld center line after electro-polishing the weld cross-section using Barker's reagent (1.8\% Fluoroboric acid in water) in as fabricated state. The material exhibit a dendritic type micro-structure with nearly spherical magnesium $(\mathrm{Mg})$ precipitates of an average size of $30 \mu \mathrm{m}$. The average grain size was nearly $55 \mu \mathrm{m}$. After analyzing the EBSD data, it was found that no significant texture was present in both longitudinal and cross-sectional direction. The respective pole figures are shown in Fig. 1.
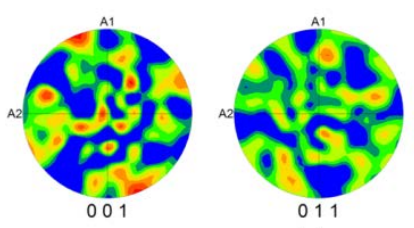

(a)
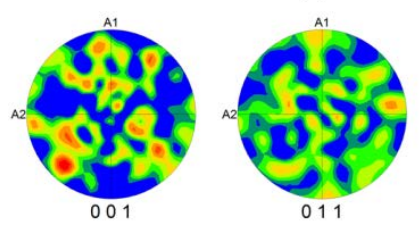

(b)
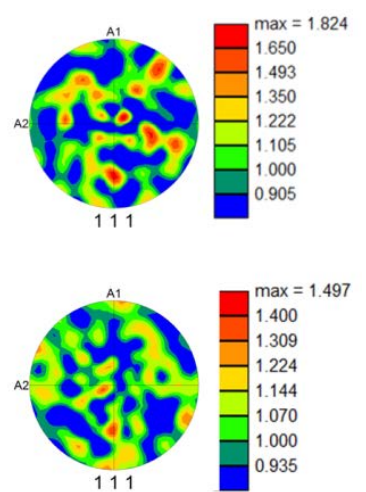
0.935
Figure 1: Pole figures of (a) cross-section and (b) longitudinal section of weld.

As expected, pores were present in the fusion part of the weld. For characterization of porosity, several high resolution images were taken and then using the open source matlab script [12], these images were converted into binary images and Watershed algorithm was used for identifying pores. A pore size data set was generated from the input of given set of images and an appropriate threshold of $30 \mu \mathrm{m}$ was applied to distinguish between the data corresponding to voids left by $\mathrm{Mg}$ precipitates while polishing and the pores resulted from welding. The statistical analysis showed that the average size of pores is $45 \mu \mathrm{m}$, which is comparable to average grain size ( 55 $\mu \mathrm{m})$. These pores were often responsible for fatigue crack initiation as illustrated and discussed later.

Table 1: Chemical composition (wt. \%)

\begin{tabular}{|l|l|l|l|l|l|l|l|l|}
\hline Material & $\mathrm{Cu}$ & $\mathrm{Si}$ & $\mathrm{Fe}$ & $\mathrm{Mn}$ & $\mathrm{Mg}$ & $\mathrm{Zn}$ & $\mathrm{Cr}$ & $\mathrm{Ti}$ \\
\hline Al-5083 & 0.03 & 0.14 & 0.25 & 0.68 & 4.32 & 0.01 & 0.11 & 0.02 \\
\hline Al-5183 & 0.00 & 0.07 & 0.17 & 0.66 & 5.03 & 0.00 & 0.07 & 0.07 \\
\hline
\end{tabular}

Table 2: Mechanical properties of Al-5183.

\begin{tabular}{|c|c|c|c|}
\hline $\begin{array}{c}\text { Proportional } \\
\text { Limit } \\
(\mathrm{MPa})\end{array}$ & $\begin{array}{c}0.2 \% \text { Yield } \\
\text { stress } \\
(\mathrm{MPa})\end{array}$ & $\begin{array}{c}\text { Tensile } \\
\text { stress } \\
(\mathrm{MPa})\end{array}$ & $\begin{array}{c}\text { Hardness, } \\
\mathrm{H}_{\mathrm{V}}\end{array}$ \\
\hline 98 & 140 & 285 & 77 \\
\hline
\end{tabular}

\section{Experimental Procedures}

Al-5083 plates of $50 \mathrm{~mm}$ thickness were cut in double $\mathrm{V}$-shape with $90^{\circ}$ groove angle (as illustrated in Fig. 2a). Then, single layer MIG welding was performed using Al-5183 as filler material at relative humidity of $40 \%$, welding current of 700-800 A, welding voltage of 33-34 $\mathrm{V}$, welding speed of $20-30 \mathrm{~cm} / \mathrm{min}$ and heat input speed of $6 \mathrm{~kJ} / \mathrm{min}$. After welding, cylindrical specimens of 5 $\mathrm{mm}$ diameter and $10 \mathrm{~mm}$ gage length (Fig. 2b) were machined from the weld bead along the longitudinal direction and then polished until the surface roughness $\left(R_{a}\right)$ of $0.2 \mu \mathrm{m}$ is achieved.

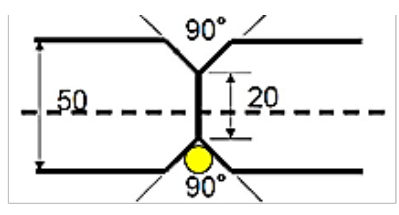

(a)

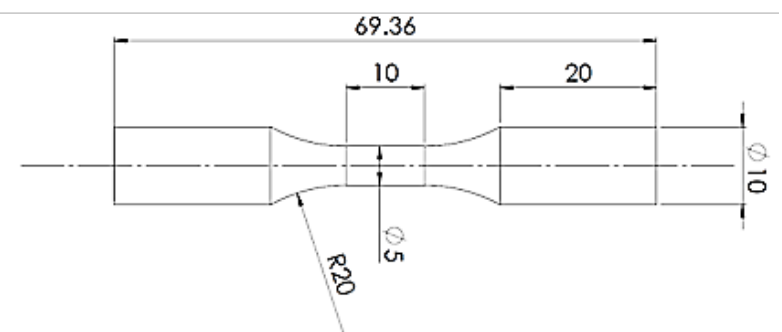

(b)

Figure 2: (a) Specifications of weld shape. Yellow circle denotes the location from where the specimens for fatigue tests were extracted (b) Geometry of cylindrical specimens used for fatigue tests.

A $50 \mathrm{kN}$ servo-hydraulic Shimadzu fatigue testing machine with a Shimadzu 4830 controller and basic windows software was used for fatigue tests. All tests were done in ambient air, at a temperature of $22{ }^{\circ} \mathrm{C}$ and at relative humidity of around $40 \%$.

To study and model the hysteresis behavior of the material, few strain-controlled fully reversed low-cycle fatigue tests were done using triangular waveform. A constant strain rate of $10^{-3} / \mathrm{sec}$ was maintained during the tests. Three different strain amplitudes $\left(\varepsilon_{\mathrm{a}}\right)$ were applied using an extensometer of $8 \mathrm{~mm}$ gage length: $0.35 \%, 0.50 \%$ and $0.80 \%$.

To study the high-cycle fatigue behavior and characterize the mean stress effect on fatigue damage, several load-controlled push-pull tests were done at different R-ratios:

$$
R=\frac{\sigma_{\min }}{\sigma_{\max }}=-1,-0.5,0.1,0.50 .7,0.8
$$


Sinusoidal waveform was used to apply cyclic loading. All tests were done in air and at a frequency of $30 \mathrm{~Hz}$. The fatigue tests were continued until the complete failure of specimen into two halves or until $10^{7}$ cycles, whichever comes first. Usually, endurance limit is defined as the stress amplitude at which $50 \%$ of the tested specimens survived a given number of cycles but due to limited number of specimens available, repetition of fatigue tests at same stress amplitude was not possible. Thus, the stress amplitude at which specimen survived $10^{7}$ cycles was considered as the endurance limit for that R-ratio.

For long crack growth tests, standard CT specimens of width (W) $39 \mathrm{~mm}$ and $7 \mathrm{~mm}$ thick (Fig. 3) were extracted from the welded part such that the notch of the CT specimen lies along the weld bead i.e. the notch face is parallel to the weld bead and the crack propagation plane is same as in cylindrical specimens. The notch shape was slightly modified so as to allow the mounting of clip gage. A pre-crack of about $3 \mathrm{~mm}$ was made by load shredding procedure such that the average crack growth rate was lower than $10^{-8} \mathrm{~m} /$ cycle.

Both $\Delta \mathrm{K}$-decreasing and $\Delta \mathrm{K}$-increasing tests were done in the range of $10^{-10} \mathrm{~m} /$ cycle to $10^{-6} \mathrm{~m} /$ cycle. $\Delta \mathrm{K}$ decreasing tests were usually followed by $\Delta \mathrm{K}$-increasing tests as described in ASTM E-647-00 standard. For $\Delta \mathrm{K}-$ decreasing tests, stepwise load shredding procedure was followed and the crack was allowed to crack by $0.5 \mathrm{~mm}$ before decreasing the load for next step.

Tests were done at three different R-ratios $(\mathrm{R}=0.1$, $0.5,0.8)$ and at a constant frequency of $50 \mathrm{~Hz}$. The crack length was measured by the travelling optical microscope (KEYENCE VHX-6000). The threshold stress intensity factor range $\left(\Delta \mathrm{K}_{\mathrm{th}}\right)$ for a particular $\mathrm{R}$ ratio was defined when the crack growth rate of $10^{-10}$ $\mathrm{m} /$ cycle was achieved.

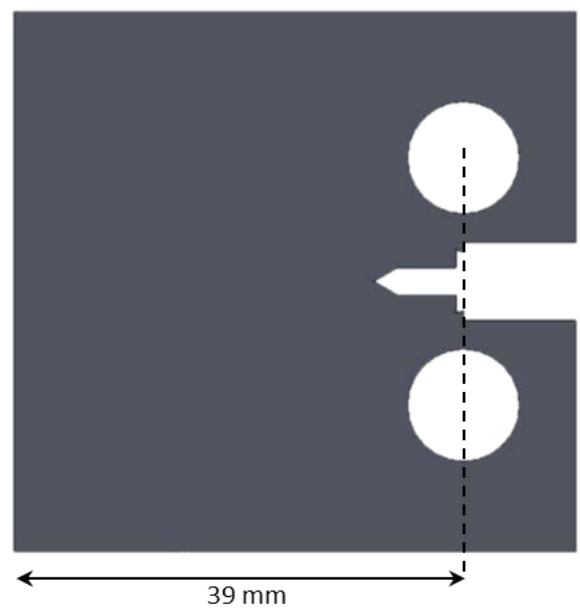

Figure 3: Geometry of CT specimen (7 mm thick) used for long crack growth tests.

JEOL JCM-6000 Scanning Electron Microscope (SEM) was used to examine the fracture surfaces of broken specimens. A Keyence digital optical microscope and a laser microscope Olympus OLS-4000 was used for topographic measurements and porosity measurements.

\section{Results}

\subsection{Load-controlled high-cycle fatigue}

The fatigue life data obtained from load-controlled high-cycle fatigue tests has been plotted in terms of stress amplitude or stress range against the total number of cycles to failure $(\Delta \sigma-\mathrm{N}$ plot, also known as Wöhler curve) and is shown in Fig. 4a. Some scatter in fatigue life data was observed but not significant enough and a single power law could be easily fitted except for $\mathrm{R}=$ 0.1 , for which bilinear plot was required to fit the experiment data. The fitting to experimental data points was done using regression analysis.

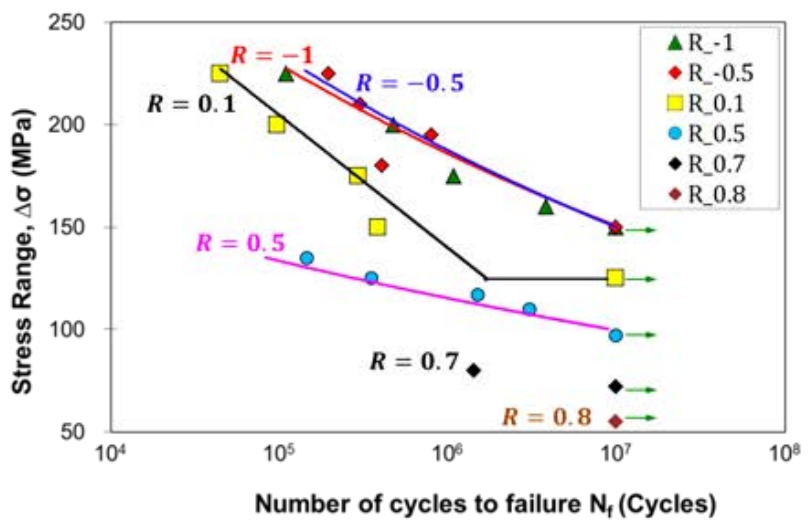

(a)

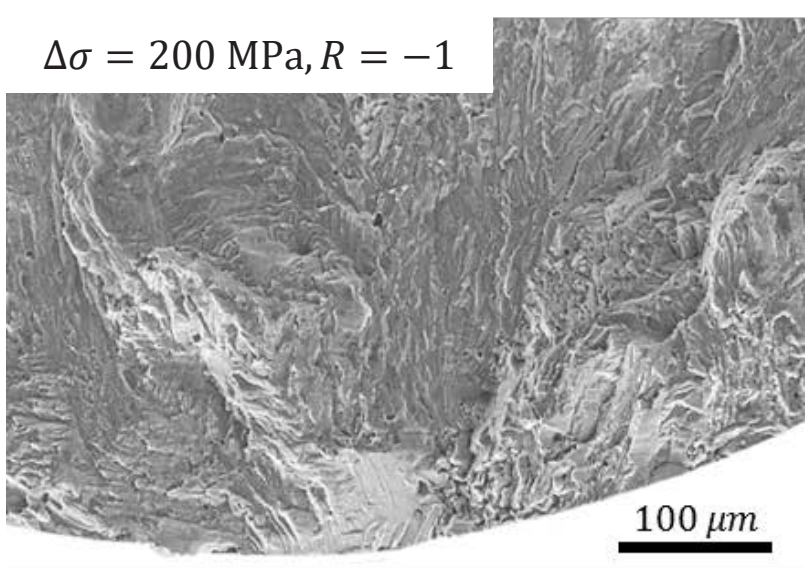

(b)

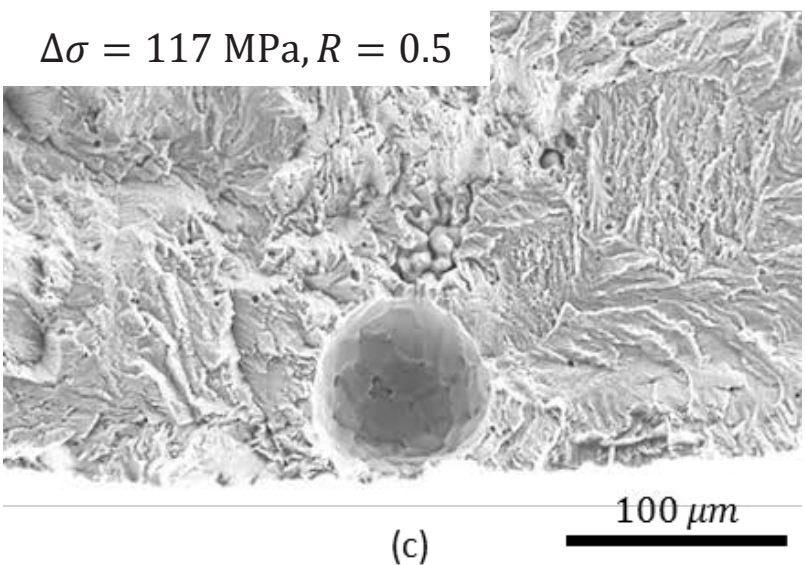

Figure 4: Whöler curve (a) and types of crack initiation: surface-induced (b) and defect-induced (sub-surface pore). 
Fatigue lives and the endurance limits, both, were decreasing with increase in R-ratio, implying the detrimental effect of mean stress on fatigue lives. However, the detrimental effect for $\mathrm{R}=-0.5$ was negligible as compared to that for $\mathrm{R}=-1$. A nonmonotonic trend in slopes of S-N curves was observed: first decreased when the R-ratio was increased from $\mathrm{R}=$ -1 to $\mathrm{R}=0.1$, then started to increase after $\mathrm{R}=0.1$. Beyond a certain $\mathrm{R}$-ratio $(\mathrm{R}>0.7)$, no fatigue failure could be observed within the investigated range of fatigue lives $\left(10^{7}\right.$ cycles).

Majority of fatigue failures at lower R-ratios $(<0.1)$ initiated from surface without any defects (Fig. 4b) while at higher R-ratios $(\geq 0.1)$, most of the fatigue failures initiated from welding defects (pores) (Fig. 4c). For the cases where the fatigue failure occurred from defects, it was observed that the defects were nearly spherical in shape and were located on/near to the surface, with a typical range for pore size between $50 \mu \mathrm{m}$ to $140 \mu \mathrm{m}$.

\subsection{Crack growth}

The crack growth points obtained for $\Delta \mathrm{K}$-decreasing and $\Delta \mathrm{K}$-increasing followed nearly the same trend as shown in Fig. 5. However, it is recommended in ASTM-E-647 that in such a case, the point of $\Delta \mathrm{K}$-increasing should only be considered for analysis and duplicate points obtained from $\Delta \mathrm{K}$-decreasing should be deleted. Two different crack growth tests were conducted for each Rratio so as to see the accuracy and preciseness of the obtained experimental results and it was found that the crack growth results obtained are precise and reliable.

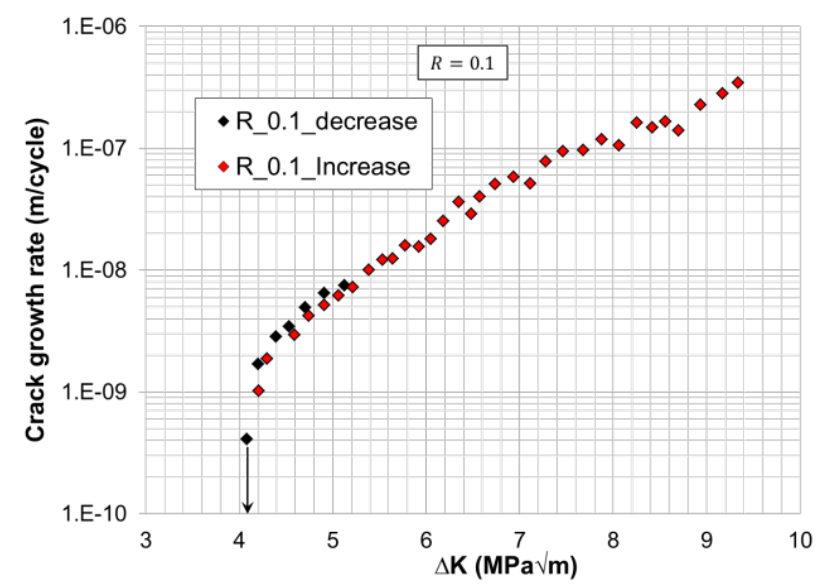

Figure 5: Crack growth data for $\Delta \mathrm{K}$-decreasing and $\Delta \mathrm{K}$ increasing for $R=0.1$.

Fig. 6 compares the crack growth rate at different $\mathrm{R}$-ratios and as expected, decrease in R-ratio decreases the fatigue crack growth rate and the threshold $\Delta K$. However, the drop in crack growth rates was less from $\mathrm{R}$ $=0.5$ to $\mathrm{R}=0.8$ as compared to that from $\mathrm{R}=0.1$ to $\mathrm{R}=$ 0.5 . For $\mathrm{R}=0.1$ and 0.5 , a definite Paris regime could be observed spanning along the significant range of $\Delta \mathrm{K}$ while for $\mathrm{R}=0.8$, Paris regime was limited to a smaller $\Delta \mathrm{K}$ range and a stage-III type of crack propagation was observed.

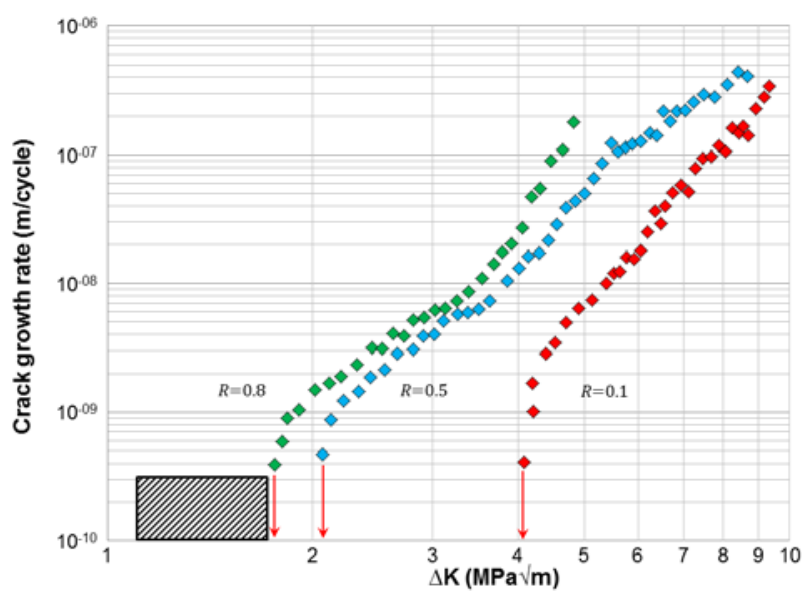

Figure 6: Long crack growth data at different R-ratios.

\section{Discussion}

\subsection{Fatigue lives}

Increase in mean stress decreases both the endurance limits and the fatigue lives with some scatter. However, plotting the true stresses instead of nominal stresses in Wöhler curve (S-N curve) did not reduce the scatter in fatigue data. The experimental fatigue data was also plotted in Goodman diagram (Fig. 7a). Data are plotted as broken (red dots) and unbroken (green dots) specimens only. Some popular empirical models available in literature, like Gerber's parabola, SmithWatson-Topper's model, Walker's model and the modified Walker's model proposed in [11] are also plotted in same plot and compared with each other. It appears that the modified Walker's model when combined with mean ductile fracture line predicts better the evolution of endurance limit.

At very high stress ratios $(\mathrm{R}>0.7)$, no fatigue failure could be observed within the investigated range of fatigue lives thus suggesting a probable saturation effect of mean stress above this R-ratio. To precise this critical R-ratio, two tests were done at $\mathrm{R}=0.7$ (two different stress amplitudes: one broken test and one nonbroken). Fig. $7 \mathrm{~b}$ compares the evolution of mean strain during a fatigue test at $\mathrm{R}=0.8$ (no fatigue failure) and $\mathrm{R}$ $=0.7$ (no fatigue failure). Mean strain was calculated from strain amplitude which was recorded during the fatigue tests using an extensometer. Although, the specimen did not fail until $10^{7}$ cycles and the tests were stopped but mean strain was continuously increasing with time for $\mathrm{R}=0.8$ while for $\mathrm{R}=0.7$, a steady state was reached. It implies the continuous accumulation of plastic strain (probably due to ratchetting) at stress ratio above $\mathrm{R}=0.7$. It is thus reasonable to say that above this $\mathrm{R}$-ratio $(\mathrm{R}=0.7)$, mean stress effect on fatigue is indeed saturated but it does not necessarily imply non-failure of specimens. Above this R-ratio (transition point), material is expected to fail due to ratchetting if the tests were continued beyond $10^{7}$ cycles.

Similar mean stress saturation effects have already been reported in some studies for e.g. in Ti alloys [13] and in steels [14]. Kovacs [14] also reported the failure 
of martensitic steels (X10CrNiMoV12-2-2) in fatigue at high mean stresses with a typical ratchetting failure at a very high stress ratio $(\mathrm{R}=0.7)$ and thus consistent with interpretation and observation in this study.

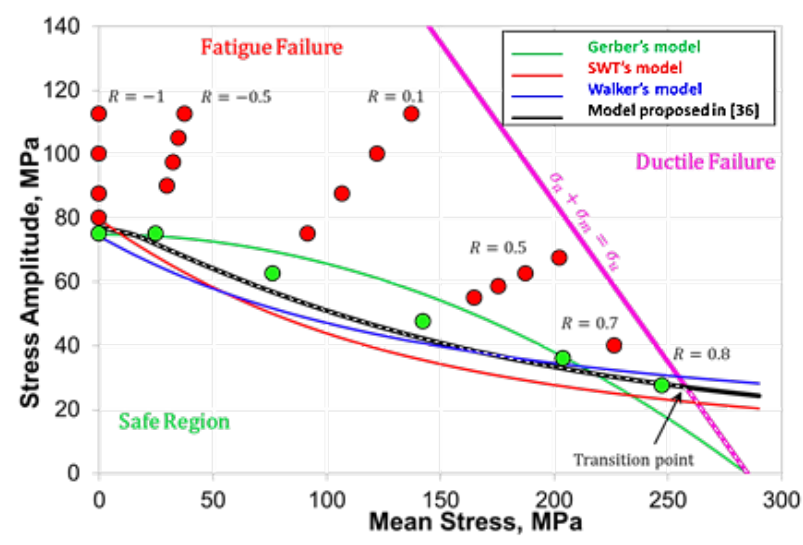

(a)

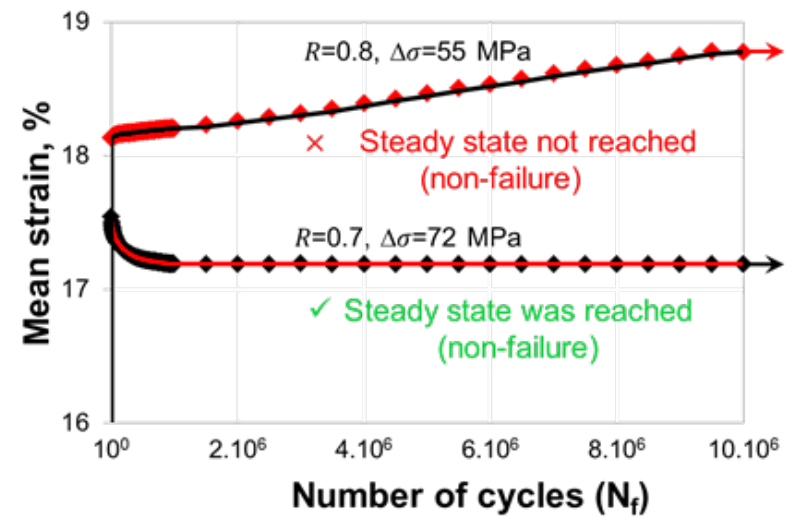

(b)

Figure 7: (a) Goodman diagram for combined experimental fatigue data. (b) Evolution of mean strain at high R-ratios.

\subsection{Crack initiation}

SEM observations of fracture surfaces revealed two types of crack initiation mechanisms:

- Surface-initiated crack initiation, dominant at lower $\mathrm{R}$ ratios $(<0.1)$

- Defect-initiated crack initiation, dominant at high R-ratios $(>0.1)$.

All defects responsible for crack initiation appeared to be gas porosities resulting from welding, owing to their nearly spherical shapes. Such porosities could have resulted from ingression of various gases into the weld pool and most susceptible one is the hydrogen gas considering its sources like moisture, hydrocarbons from contaminants on parent material and many others. But the exact mechanism is not yet fully understood. The fraction of specimens with defect-initiated failures was calculated for each $\mathrm{R}$ ratio by dividing the total number of specimens initiated from pores to the total number of fatigue tests done at that R-ratio and a dependence of crack initiation site on R-ratio was found: \% of defect- initiated failures increased with increase in R-ratio (Fig. 8).

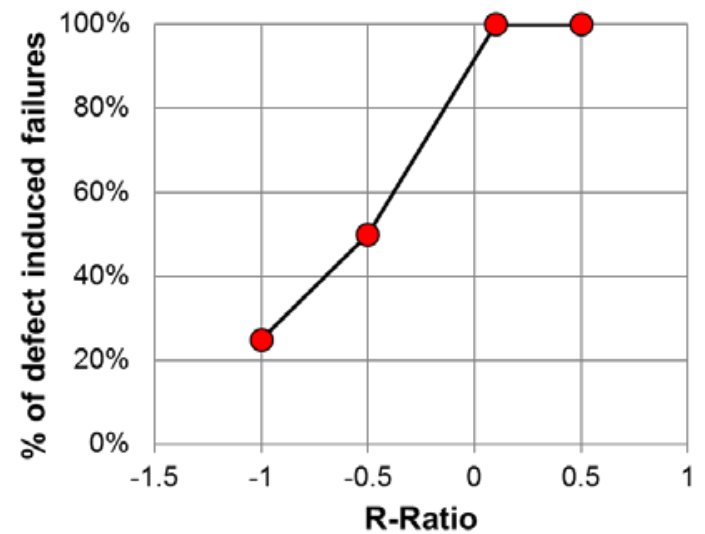

Figure 8: Evolution of fraction of defect-induced crack initiations at different R-ratios.

Of all the defects present in the material, only the ones located on or near to the surface were mainly responsible for crack initiation, implying the significant role of surface or sub-surface pores on fatigue damage. The severity of sub-surface pores has also been studied numerically by many authors and it was concluded that the pores touching the surface are always more prone to initiate damage as compared to other pores $[11,15]$. It is already been shown that the stress concentration factor $\left(\mathrm{K}_{\mathrm{t}}\right)$ varies with the position of pore with respect to surface. The $K_{t}$ value is highest when the pore is located near to the surface as compared to the one located far away. Such a variation of $\mathrm{K}_{\mathrm{t}}$ with pore position does not change with pore size. Higher $K_{t}$ induces inhomogeneous stress-strain field around the pores and higher cyclic plasticity at the edge of pore, thereby making it more prone to fatigue damage initiation. Also, high R-ratio, which means higher peak stress, promotes local plastic flow around the pore. These arguments can probably explain preferential crack initiation from defects located on or near to the surface in cases of defect induced failures and their dominance at high Rratios.

Usually it is expected that increase in mean-stress should decrease crack initiation time because of the plastic flow that occurred during the first ramp load of the cycle. Also, the presence of pores could have reduced the crack nucleation time and thus the combined effect should reduce the crack initiation time significantly. It is thus expected that at $\mathrm{R}=0.8$, a crack should have initiated but no failure was observed, probably because of the insufficient crack driving force $(\Delta \mathrm{K})$ so that the crack, if initiated, could not have propagated and the same could be verified using crack growth characteristics as discussed next.

\subsection{Crack growth}

Mean stress certainly seems to affect crack growth rates and reasons for this has already been known i.e. crack closure effects: plasticity induced crack closure, 
roughness-induced crack closure and oxide-induced crack closure.

SEM observations of fracture surfaces at different stress ratios revealed effect of mean stress on fracture surfaces. For low stress ratios $(\mathrm{R}<0.1)$, smooth and clear fatigue striations could be observed (Fig. 9a) while for higher stress ratios $(\mathrm{R}>0.1)$, such smooth striations were difficult to locate (Fig. 9b). The probable reason could be the lower $\Delta \mathrm{K}$ at high R-ratios and could imply the role of plasticity-induced crack closure [16].

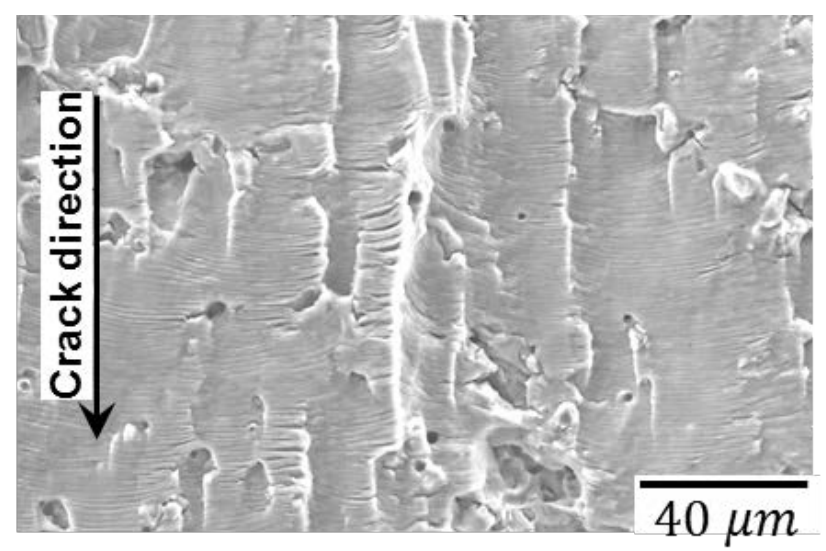

(a)

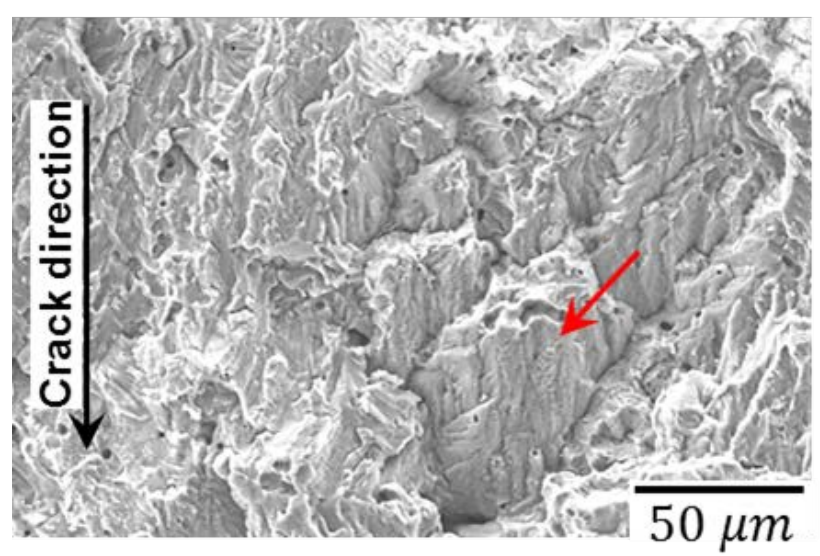

(b)

Figure 9: Striations as observed on fracture surfaces at different R-ratios: (a) $R=-\mathbf{0 . 5}$ and (b) $R=0.7$.

The fracture surface roughness was also compared at different stress ratios. The fracture surface at higher Rratio appeared to be rougher as compared to that at lower R-ratio and thus suggest the role of asperity-induced or roughness induced crack closure [17]. An attempt was made to quantify this change in surface roughness using the Olympus LASER microscope. The ductile failure region of the broken specimens was carefully removed so as to avoid any interference with the lens of the microscope. Standard procedures were adopted for measurements using the recommended cut-off value $(2.5$ $\mathrm{mm}$ ) to filter longer wavelength of the roughness (ISO 4288-1996). Five measurements were done at each stress ratio (R-ratio) and then an average roughness value $\left(R_{a}\right)$ was calculated and is plotted in Fig. 10 for different Rratios. It is evident that the roughness value $\left(R_{a}\right)$ tends to increase with increase in R-ratio with saturating effect at very high $\mathrm{R}$ ratios.

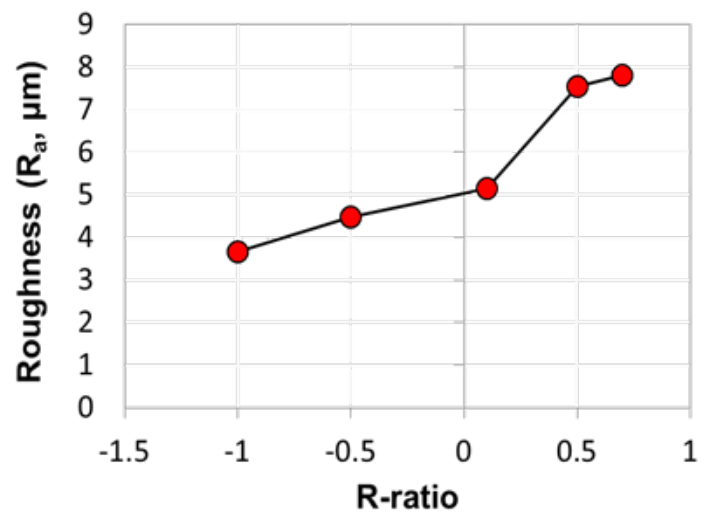

Figure 10: Estimated trend in mean value of roughness (Ra, $\mu \mathrm{m})$ of fracture surfaces at different R-ratios.

To understand better the crack growth from defects, stress intensity factor was calculated for each defect responsible for fatigue crack initiation using the Murakami's "Varea" model [8]:

$$
\Delta K=\beta \Delta \sigma \sqrt{\pi \sqrt{\text { area }}}
$$

Where $\beta=0.5$ for internal defect and $\beta=0.65$ for surface touching defect. The stress range $(\Delta \sigma)$ for negative R-ratios was calculated considering only the tensile part of the load cycle, since compressive load cycle do not contribute to crack growth. The initial stress intensity factor for the defects typically lies within the range of 1.1-1.7 $\mathrm{MPa} \sqrt{\mathrm{m}}$ for different R-ratios. The same has also been marked by hatched black box in Fig. 6. It is quite clear that the $\Delta \mathrm{K}$ for these defects lie below the respective $\Delta \mathrm{K}_{\mathrm{th}}$ at each $\mathrm{R}$-ratio.

Considering the largest observed defect responsible for fatigue failures (i.e. $100 \mu \mathrm{m}$ ) and the largest possible stress range that can be applied at $\mathrm{R}=0.8$ (i.e. $56 \mathrm{MPa}$ ), the stress intensity factor calculated using Eq. 2 came out to be $0.6 \mathrm{MPa} \sqrt{\mathrm{m}}$. This initial stress intensity factor range is way lower than the $\Delta \mathrm{K}_{\text {th }}$ for $\mathrm{R}=0.8$ and probably is also lower than the intrinsic threshold value for crack propagation for this material. Thus at this Rratio, even though it is expected that a crack should have initiated but it may not propagate due to very low crack driving force.

But given the fact that the size of defects are comparable to that of average grains size, the crack initiating from these defects cannot analyzed using long crack growth data. The crack initiating from defects are the microstructurally short crack and short crack growth data may be required to explain initiation from these defects. Many studies [18-19] have shown that the short crack can grow at a faster rate than the long cracks, even below $\Delta \mathrm{K}_{\text {th }}$, which might also be the case here. Therefore, to understand better the contribution of crack initiation and crack propagation in total fatigue live for defect-induced failures, it is required to have some data on short crack growth. Such short crack growth tests are still in progress. 


\section{Conclusions and further work}

Based on the work done till now, following conclusions could be drawn:

- Cyclic loading with mean-stress decrease the fatigue lives, due to combine effects of the crack closure effects and also probably due to the reduction in crack-nucleation time.

- A saturation effect of mean-stress on fatigue was observed at $\mathrm{R}>0.7$, with no fatigue failure above this R-ratio.

- Mean stress also tends to control crack initiation sites in metals containing defects: defect-induced failures were dominant at high R-ratios, with nearly all of the defects located on/near the surface.

- The probable reason for higher fraction of defect-induced failures at higher R-ratio could be enhanced local cyclic plasticity due to high stress concentration factor associated with them.

Long crack growth data alone could not possibly explain the crack growth behavior of cracks initiation from naturally occurring defects inside the material. It is so because the size of defects was comparable to the average grain size and thus should be treated as microstructurally short cracks. Short crack growth tests are in progress.

The authors are thankful to the Japanese research funding agency (JST) for funding this project through its Crossministerial Strategic Innovation Promotion (SIP), "Structural Materials for Innovation" program.

\section{References}

1. R. S. Mishra, Z.Y. Ma, Mater. Sci. Eng. R Rep. 50, 1-78 (2005)

2. I. Bunaziv, O.M. Akselsen, A. Salminen, A. Unt, J. Mater. Process. Technol. 233, 107-114 (2016)

3. H. Jakubczak, G. Glinka, Int. J. Fatigue 8, 51-57 (1986)

4. U.Brandt, F. Lawrence, C.M. Sonsino, Fatigue Fract. Eng. Mater. Struct. 24, 117-126 (2001)

5. H.R. Ammar, A.M. Samuel, F.H. Samuel, Mater. Sci. Eng., A 473, 65-75 (2008)

6. M. Couper, A. Neeson, J. Griffiths, Fatigue Fract. Eng. Mater. Struct. 13, 213-227 (1990)

7. Q.G. Wang, D. Apelian, D.A. Lados, J. Light Met. 1, 73-81 (2001)

8. Y. Murakami, Metal defects: Effect of small defects and nonmetallic inclusions (2002)

9. Z.Lei, Y. Hong, J. Xie, C. Sun, A. Zhao, Mater. Sci. Eng., A 558, 234-241 (2012)

10. P. Threadgill, A. Leonard, H. Shercliff, P. Withers, Int. Mater. Rev. 54, 49-93 (2009)
11. V. Gaur, M. Enoki, T. Okada, S. Yomogida, Int. J. Fatigue 107, 119-129 (2018)

12. A. Rabbani, S. Jamshidi, S. Salehi, J. Pet. Sci. Eng. 123, 164-171 (2014)

13. R.J. Morrissey, D.L. McDowell, T. Nicholas, Mech. Time-Depend. Mater. 2, 195-210 (1998)

14. S. Kovacs, T. Beck, L. Singheiser, Int. J. Fatigue 49, 90-99 (2013)

15. Z. Xu, W. Wen, T. Zhai, Metall. Mater. Trans. A 43, 2763-2770 (2012)

16. W. Elber, Eng. Fract. Mech. 2, 37-45 (1970)

17. S. Suresh, R. Ritchie, Metall. Mater. Trans. A 13, 1627-1631 (1982)

18. K.J. Miller, Fatigue Fract. Eng. Mater. Struct. 10, 75-91 (1987)

19. A. McEvily, Trans. on Eng. Sci. 13, 93-107 (1996) 